\title{
Analisis Perubahan Temperatur Permukaan Wilayah Surabaya Timur Tahun 2001-2016 Menggunakan Citra LANDSAT
}

\author{
Anoraga Jatayu dan Cahyono Susetyo \\ Departemen Perencanaan Wilayah dan Kota, Fakultas Teknik Sipil dan Perencanaan, Institut Teknologi \\ Sepuluh Nopember (ITS) \\ e-mail: cahyono_s@urplan.its.ac.id
}

\begin{abstract}
Abstrak-Urban Heat Island (UHI) adalah suatu fenomena dimana suhu udara pada wilayah yang padat bangunan atau kawasan perkotaan lebih tinggi daripada suhu udara di wilayah dengan ruang terbuka yang lebih banyak atau wilayah pedesaan. Salah satu cara untuk mengamati terjadinya fenomena UHI adalah dengan mengamati dinamika suhu permukaan yang terdapat pada suatu wilayah dalam beberapa periode. Penelitian ini menggunakan analisis remote sensing untuk dapat mengkonversikan nilai-nilai digital number pada citra satelit LANDSAT masing-masing periode menjadi nilai land surface temperature/suhu permukaan suatu wilayah serta analisis overlay untuk mengetahui dinamika perubahan suhu permukaan dari beberapa periode waktu yang telah ditentukan. Berddasarkan hasil penelitian dapat diketahui bahwa terdapat peningkatan yang cukup signifikan yaitu selama periode tahun 2001-2016 telah terjadi peningkatan sebesar $6,612^{\circ} \mathrm{C}$ atau sekitar $\mathbf{2 5 , 4 1 \%}$ dari nilai suhu permukaan rata-rata pada tahun 2001 . Daerah yang memiliki intensitas peningkatan suhu permukaan tertinggi merupakan bagian timur dan selatan wilayah Surabaya Timur.
\end{abstract}

Kata Kunci-Urban Heat Island, Suhu Permukaan, Remote Sensing.

\section{PENDAHULUAN}

$\mathrm{U}$ RBAN Heat Island (UHI) adalah suatu fenomena dimana suhu udara pada wilayah yang padat bangunan atau kawasan perkotaan lebih tinggi daripada suhu udara di wilayah dengan ruang terbuka yang lebih banyak atau wilayah pedesaan. Pada umumnya suhu udara yang tertinggi akan terdapat di pusat kota dan menurun secara bertahap kearah pinggir kota sampai ke rural area (wilayah pedesaan). Urban Heat Island atau pulau panas perkotaan terjadi karena adanya perbedaan dalam pemakaian energi, penyerapan, dan pertukaran panas antara daerah perkotaan dengan pedesaan [1][2][3]. Urban Heat Island dapat berdampak pada berkurangnya kenyamanan hidup pada suatu kota akibat suhu udara yang semakin meningkat. Selain itu, Urban Heat Island (UHI) juga dapat menyebabkan perubahan iklim secara mikro akibat adanya perubahan suhu, kelembapan, dan tekanan udara di wilayah tersebut.

Salah satu faktor penyebab Urban Heat Island adalah wilayah padat bangunan dan minim ruang terbuka sehingga mempengaruhi material penutup permukaan lahan yang menyebabkan meningkatnya temperatur permukaan, hal ini merupakan salah satu kecenderungan pola penggunaan lahan di kawasan perkotaan. Dalam hal ini, dapat dikatakan bahwa fenomena Urban Heat Island dapat diamati perkembangan dan intensitasnya berdasarkan dinamika perubahan temperatur permukaan di wilayah tersebut

Berdasarkan pengamatan yang dilakukan pada beberapa kota besar di Amerika Serikat, peningkatan temperatur permukaan terjadi seiring dengan semakin luasnya kota tersebut berkembang dan maju. Hal tersebut ditandai dengan semakin banyaknya lahan yang dimanfaatkan sebagai lahan terbangun tanpa memperhatikan proporsi ruang terbuka. Selain itu, pada kota-kota yang mengalami peningkatan temperatur permukaan terdapat kecenderungan memiliki suhu yang lebih tinggi $3-4^{\circ} \mathrm{C}$ dibandingkan dengan wilayah di sekitarnya. Selain itu, kota tersebut juga lebih rawan terkena serangan gelombang panas (heatwave) pada musim panas.

Pada penelitian ini lokasi yang digunakan sebagai studi kasus adalah Kota Surabaya, lebih tepatnya wilayah Surabaya Timur dimana dalam 15 tahun terakhir ini mengalami perkembangan yang cukup pesat dan terdapat banyak pembangunan. Fenomena Urban Heat Island yang terjadi di Kota Surabaya ditunjukkan dengan rata-rata suhu udara di Kota Surabaya yaitu sekitar $24^{\circ} \mathrm{C}$ pada rata-rata minimum dan $35^{\circ} \mathrm{C}$ pada rata-rata maksimum. Kondisi suhu udara di Kota Surabaya secara umum mengalami peningkatan sebesar 1-1,4\% sejak 5 tahun terakhir. Berdasarkan hasil analisis tren suhu yang dilakukan oleh BMKG, wilayah Kota Surabaya memiliki tren peningkatan suhu yang tertinggi, yaitu sebesar $0,5^{\circ} \mathrm{C} / 10$ tahun [4].

Kenaikan temperatur di Kota Surabaya ini membuat perbedaan temperatur di Kota Surabaya dengan wilayah di sekitarnya menjadi lebih besar, antara lain dengan Kabupaten Gresik yang memiliki suhu rata-rata maksimum sebesar $33^{\circ} \mathrm{C}$ dan Kabupaten Sidoarjo dengan suhu rata-rata maksimum sebesar $33,3^{\circ} \mathrm{C}$. Kenaikan tersebut diiringi dengan kecenderungan intensitas Urban Heat Island yang semakin meningkat dan luasan area terdampak yang semakin besar. [5][6],

Terjadinya akselerasi pembangunan yang cukup cepat di Wilayah Surabaya terutama pada Surabaya Timur menyebabkan semakin banyaknya terjadi peningkatan luasan lahan terbangun tanpa diimbangi dengan proporsi lahan terbuka yang cukup. Hal ini dapat menyebabkan meningkatnya suhu permukaan oleh karena lahan terbangun memiliki penutup tanah yang cenderung menyerap dan sulit melepaskan panas sehingga akan semakin meningkatkan intensitas dan luasan 
terjadinya fenomena Urban Heat Island. Oleh karena itu, penelitian ini perlu dilakukan untuk mengamati kecenderungan perubahan temperatur permukaan pada wilayah Surabaya Timur seiring dengan semakin pesatnya pembangunan yang terjadi.

\section{METODE PENELITIAN}

\section{A. Metode Pengumpulan Data}

Data yang digunakan pada penelitian ini adalah data citra satelit LANDSAT 7 untuk mendapatkan nilai temperatur permukaan pada periode tahun 2001, 2006, dan 2011 serta LANDSAT 8 untuk mendapatkan nilai temperatur permukaan pada periode tahun 2016. Pengumpulan data dilakukan melalui survei sekunder dengan melakukan pengunduhan citra LANDSAT pada https://earthexplorer.usgs.gov/ berdasarkan periode waktu yang telah ditentukan

\section{B. Metode Analisis}

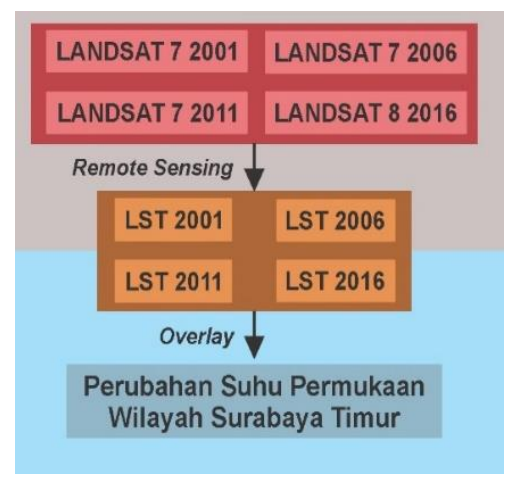

Gambar 1. Alur Analisis Penelitian.

Terdapat 2 tahapan analisis yang dilakukan dalam penelitian ini, yaitu pengolahan citra satelit LANDSAT 7 dan 8 untuk mendapatkan nilai suhu permukaan dan analisis overlay untuk mengetahui perubahan suhu permukaan pada wilayah Surabaya Timur.

\section{Identifikasi Nilai Suhu Permukaan Surabaya Timur}

Untuk memperoleh nilai suhu permukaan dari data citra LANDSAT terdapat beberapa langkah yang harus dilakukan, yaitu dengan mengekstrak nilai DN (Digital Number) dari band thermal yang memiliki kepekaan terhadap geothermal (Band 6 VCID 1 danVCID 2 pada LANDSAT 7 serta Band 10 dan 11 pada LANDSAT 8) [7][8].

- Konversi nilai DN menjadi Spektral Radian

Nilai spektral radian merupakan fluks radian per unit pada sudut tertentu yang diradiasikan oleh suatu objek ke arah tertentu. Nilai spektral radian pada LANDSAT 7 dihitung dengan rumus berikut:

$L_{\Lambda}=\frac{L \max -L \min }{\text { QCALmax }-Q C A L \min } x(Q C A L-Q C A L \min )+L$ min

Sedangkan untuk LANDSAT 8 sebagai berikut:

$L_{K}=M_{L} Q C A L+A_{L}$

Dimana:

$\mathrm{L}_{\kappa} \quad=$ Spektral radian Band $\mathrm{x}\left(\right.$ watts $/\left(\mathrm{m}^{2} * \mathrm{srad}^{*} \mu \mathrm{m}\right)$

QCAL = Nilai piksel citra satelit band $\mathrm{x}(\mathrm{DN})$

Lmax = Spektral radian QCALmin
Lmin = Spektral radian QCALmax

QCALmax $=$ Nilai kalibrasi maksimum dari nilai piksel citra

QCALmin $=$ Nilai kalibrasi minimum dari nilai piksel citra

$\mathrm{M}_{\mathrm{L}}=$ Band-specific multiplicative rescaling factor

- Konversi nilai Spektral Radian menjadi nilai Brightness Temperature

Brightness Temperature merupakan nilai suhu permukaan berdasarkan pengukuran satelit sebelum dilakukan penghitungan lebih lanjut menggunakan nilai emisivitas. Nilai brightness temperature dihitung dengan formula berikut:

$T_{b}=\frac{K_{2}}{\ln \left(\frac{K_{1}}{L_{\Lambda}}+1\right)}-273,15$

Dimana:

$\mathrm{Tb}=$ Temperatur kecerahan $(\mathrm{oC})$

$\mathrm{K} 1=$ Konstanta kalibrasi

$\mathrm{K} 2$ = Konstanta kalibrasi

$\mathrm{L} \kappa=$ Spektral Radian dalam (watts $/(\mathrm{m} 2 * \operatorname{srad} * \mu \mathrm{m})$

Nilai 273,15 yang terdapat pada formula tersebut merupakan nilai yang dimasukkan untuk melakukan konversi satuan pengukuran suhu dari Kelvin menjadi satuan derajat Celcius.

- Menghitung nilai suhu permukaan

Nilai suhu permukaan dihitung berdasarkan nilai brightness temperature yang kemudian dilakukan penghitungan lebih lanjut dengan memperhatikan nilai emisivitas. Nilai suhu permukaan Surabaya Timur dihitung dengan formula berikut:

$L S T=\frac{T_{B}}{1}+w *\left(\frac{T_{B}}{p}\right) * \ln (\varepsilon)$

Dimana:

$\mathrm{Tb}=$ Brightness Temperature hasil rekaman citra satelit

$\mathrm{w}=$ Panjang gelombang dari emitted radiance $(11,5 \mu \mathrm{m})$

$\mathrm{p}=\mathrm{h} * \mathrm{c} / \mathrm{s}(1,438 * 10-2 \mathrm{mK})$

$\varepsilon=$ emisivitas

$\mathrm{h}=$ Konstanta Planck $(6,626 * 10-34 \mathrm{Js})$

$\mathrm{c}=$ velocity of light $(2,998 * 108 \mathrm{~m} / \mathrm{s})$

$\mathrm{s}=$ Konstanta Boltzman $(1,38 * 10-23 \mathrm{~J} / \mathrm{K})$

Tabel 1.

Unit Conversion Coefficient LANDSAT 7

\begin{tabular}{|c|c|c|c|c|c|c|}
\hline Band TIR & Lmax & Lmin & $\begin{array}{c}Q Q C \\
A L \\
\max \end{array}$ & $\begin{array}{l}Q C \\
A L \\
\min \end{array}$ & $K_{I}$ & $K_{2}$ \\
\hline 6 VCID 1 & 17,04 & 0,00 & 255 & 1 & $\begin{array}{c}666, \\
09\end{array}$ & $\begin{array}{c}1282, \\
71\end{array}$ \\
\hline 6 VCID 2 & 12,65 & 3,20 & 255 & 1 & $\begin{array}{c}666, \\
09\end{array}$ & $\begin{array}{c}1282 \\
71\end{array}$ \\
\hline
\end{tabular}

Tabel 2.

Unit Conversion Coefficient LANDSAT 8

\begin{tabular}{|c|c|c|c|c|c|c|}
\hline Band TIR & Lmax & Lmin & $\begin{array}{c}Q Q C \\
A L \\
\max \end{array}$ & $\begin{array}{l}Q Q C \\
A L \\
\text { min }\end{array}$ & $K_{I}$ & $K_{2}$ \\
\hline 6 VCID 1 & 17,04 & 0,00 & 255 & 1 & $\begin{array}{c}666, \\
09\end{array}$ & $\begin{array}{c}1282 \\
71\end{array}$ \\
\hline 6 VCID 2 & 12,65 & 3,20 & 255 & 1 & $\begin{array}{c}666, \\
09\end{array}$ & $\begin{array}{c}1282 \\
71\end{array}$ \\
\hline
\end{tabular}


D. Analisis Perubahan Suhu Permukaan Wilayah Surabaya Timur Periode Tahun 2001-2016

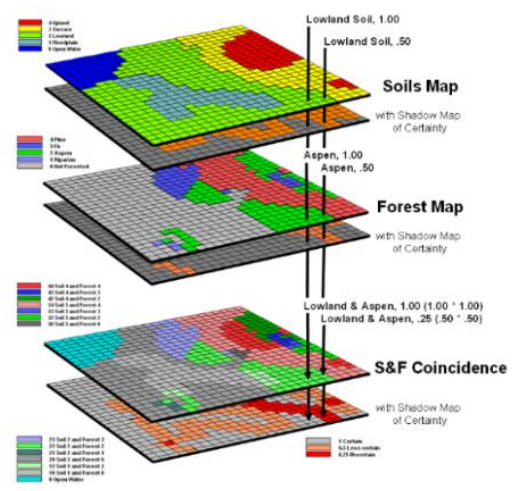

Gambar 2. Ilustrasi Analisis Overlay.

Dalam identifikasi suhu permukaan yang dilakukan melalui pengolahan data citra LANDSAT 7 dan 8, didapatkan suhu permukaan pada periode tahun 2001, 2006, 2011, dan 2016. Keempat basis data tersebut kemudian akan dianalisis lebih lanjut untuk mengetahui perubahan suhu permukaan yang terjadi selama kurun waktu tersebut. Dalam melakukan hal tersebut dilakukan analisis overlay untuk menumpang-tindihkan keempat basis data tersebut sehingga muncullah suatu basis data terbaru yang mampu menyimpan informasi dari keempat basis data awal. Pada proses overlay ini juga dilakukan penghitungan untuk mengetahui agregat suhu permukaan pada suatu kawasan sehingga dapat mengetahui kawasan yang mengalami perubahan suhu permukaan paling rendah maupun tinggi [9].

\section{HASIL DAN DISKUSI}

\section{A. Suhu Permukaan Wilayah Surabaya Timur Periode Tahun} 2001-2016

Berdasarkan hasil identifikasi Suhu Permukaan (Land Surface Temperature) yang telah dilakukan dengan analisis remote sensing pada citra LANDSAT 7 dan LANDSAT 8 periode 2001, 2006, dan 2016, dapat diketahui persebaran suhu permukaan selama periode tahun 2001-2016 di wilayah Surabaya Timur. Pada periode tahun 2001, persebaran suhu permukaan di wilayah Surabaya Timur adalah antara 16,64 $31,65^{\circ} \mathrm{C}$ dengan rata-rata suhu permukaan sebesar $24,995^{\circ} \mathrm{C}$. Pada periode tahun 2006, persebaran suhu permukaan di wilayah Surabaya Timur adalah antara $20,95-32,29^{\circ} \mathrm{C}$ dengan rata-rata suhu permukaan sebesar $26,035^{\circ} \mathrm{C}$. Pada periode tahun 2011, persebaran suhu permukaan di wilayah Surabaya Timur adalah antara $21,07-33,14^{\circ} \mathrm{C}$ dengan rata-rata suhu permukaan sebesar $27,11^{\circ} \mathrm{C}$. Sedangkan pada periode tahun 2016, persebaran suhu permukaan di wilayah Surabaya Timur adalah antara $24,57-36,39^{\circ} \mathrm{C}$ dengan rata-rata suhu permukaan sebesar $31,60^{\circ} \mathrm{C}$.
Tabel 3

Persebaran Suhu Permukaan Wilayah Surabaya Timur

\begin{tabular}{cccc}
\hline \hline No. & Tahun & LST & Presentase (\%) \\
\hline 1. & 2001 & $<18{ }^{\circ} \mathrm{C}$ & 0.120 \\
& $18-23{ }^{\circ} \mathrm{C}$ & 24.927 \\
& $23-28^{\circ} \mathrm{C}$ & 69.627 \\
& $28-33^{\circ} \mathrm{C}$ & 5.326 \\
& $>33^{\circ} \mathrm{C}$ & 0.000 \\
2. & $<18{ }^{\circ} \mathrm{C}$ & 0.000 \\
& & $18-23{ }^{\circ} \mathrm{C}$ & 15.554 \\
& $23-28{ }^{\circ} \mathrm{C}$ & 74.968 \\
& $28-33^{\circ} \mathrm{C}$ & 9.477 \\
& $>33^{\circ} \mathrm{C}$ & 0.000 \\
3. & $<18{ }^{\circ} \mathrm{C}$ & 0.000 \\
& & $18-23{ }^{\circ} \mathrm{C}$ & 3.641 \\
& $23-28{ }^{\circ} \mathrm{C}$ & 61.689 \\
& & $28-33{ }^{\circ} \mathrm{C}$ & 34.670 \\
& & $>33^{\circ} \mathrm{C}$ & 0.000 \\
4. & $<18{ }^{\circ} \mathrm{C}$ & 0.000 \\
& & $18-23{ }^{\circ} \mathrm{C}$ & 0.000 \\
& & $23-28{ }^{\circ} \mathrm{C}$ & 13.565 \\
& & $28-33^{\circ} \mathrm{C}$ & 65.123 \\
& & $>33^{\circ} \mathrm{C}$ & 21.313 \\
\hline \hline
\end{tabular}

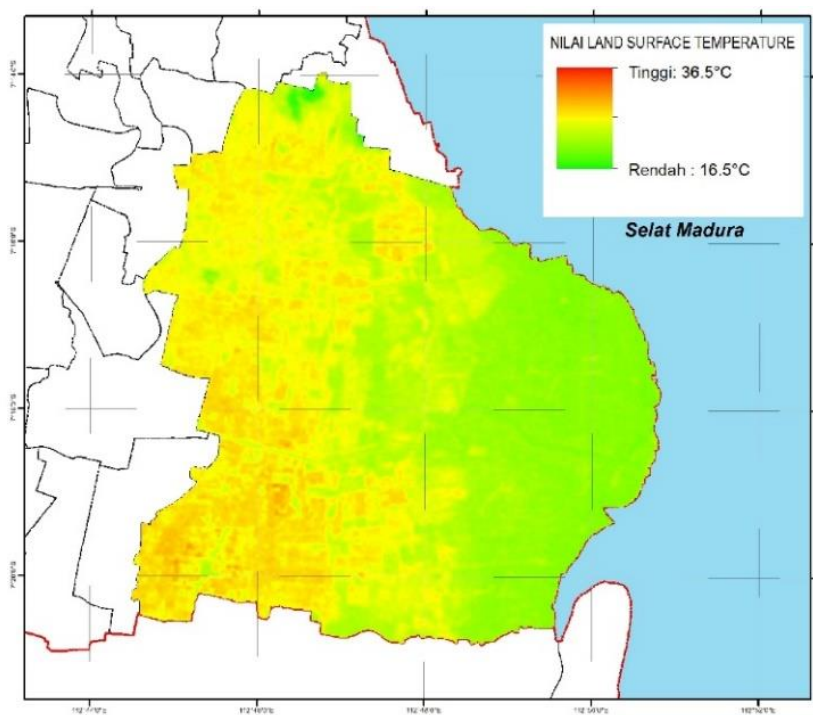

Gambar 3. Persebaran Suhu Permukaan Tahun 2001.

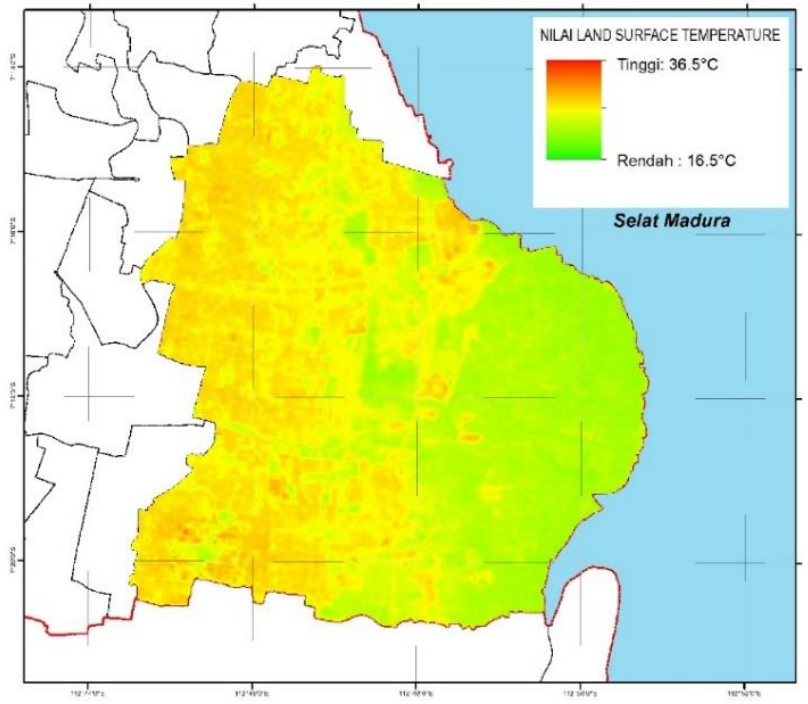

Gambar 4. Persebaran Suhu Permukaan Tahun 2006. 


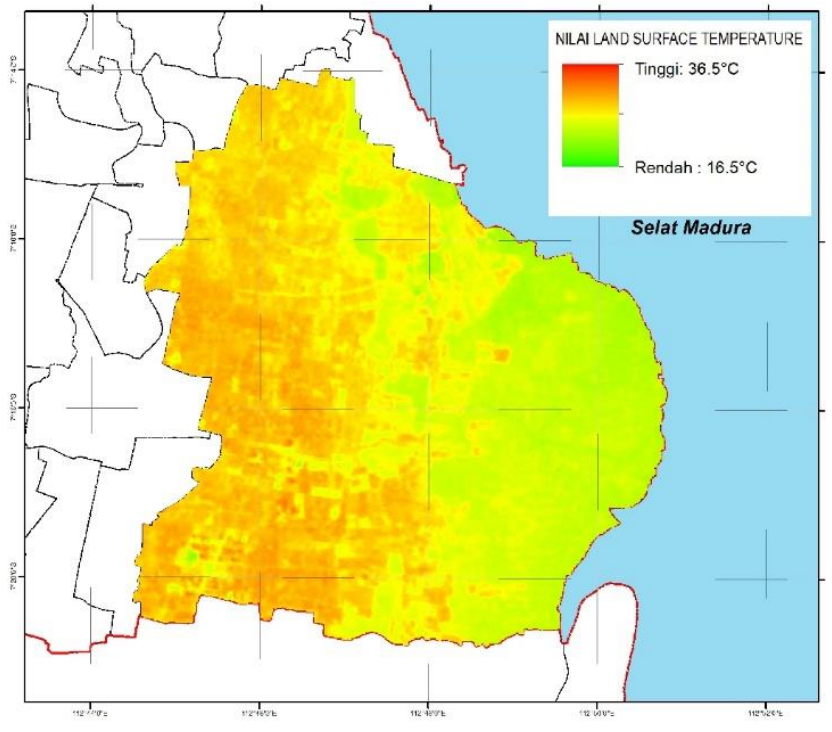

Gambar 5. Persebaran Suhu Permukaan Tahun 2011

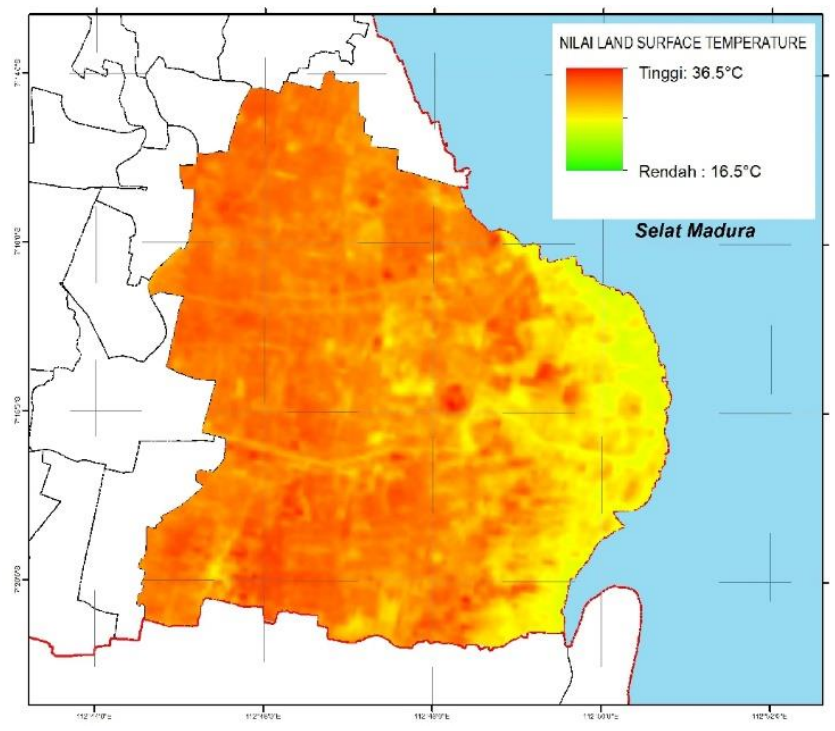

Gambar 6. Persebaran Suhu Permukaan Tahun 2016.

\section{B. Analisis Perubahan Suhu Permukaan Wilayah Surabaya Timur Periode 2001-2016}

Berdasarkan hasil analisis yang telah dilakukan, dapat diketahui bahwa terjadi tren peningkatan suhu permukaan dari tiap periode. Hal tersebut ditandai dengan peningkatan rata-rata suhu permukaan dan semakin meningkatnya presentase luasan wilayah yang memiliki suhu permukaan tinggi. Pada periode tahun $2001-2006$ terjadi peningkatan sebesar $1,041^{\circ} \mathrm{C}$ atau sebanyak 3,99\%. Pada periode tahun 2006 - 2011 terjadi peningkatan suhu permukaan sebesar $1,075^{\circ} \mathrm{C}$ atau sebanyak 3,97\%. Kemudian pada periode tahun 2011 - 2016 terjadi peningkatan suhu permukaan yang paling signifikan yaitu sebesar $4,496^{\circ} \mathrm{C}$ atau sebanyak $14,22 \%$.

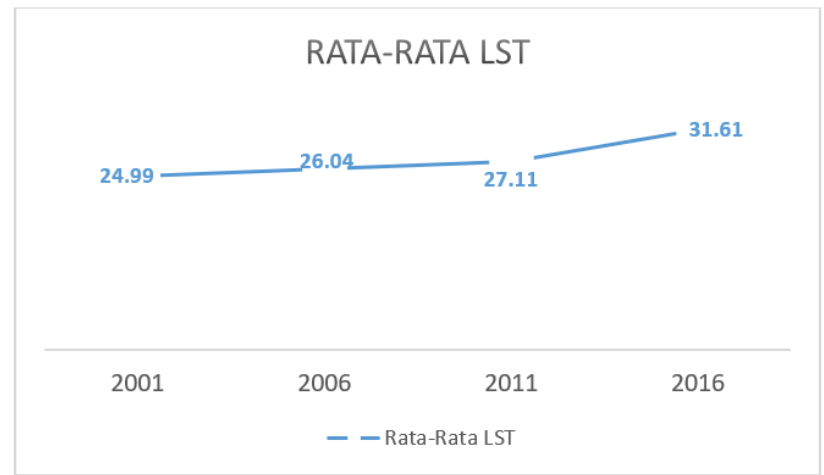

Gambar 7. Grafik Kenaikan Rata-Rata Suhu Permukaan Surabaya Timur.

Besaran kenaikan suhu permukaan di wilayah Surabaya Timur pada periode tahun 2001-2016 terjadi cukup beragam dengan tingkat kenaikan $0-13^{\circ} \mathrm{C}$. Rincian presentase dan persebaran kenaikan suhu permukaan di wilayah Surabaya Timur periode tahun 2001-2016 dapat dilihat pada Tabel 4 dan Gambar 8.

Tabel 4.

Presentase Kenaikan Suhu Permukaan Surabaya Timur

\begin{tabular}{ccc}
\hline \hline No. & Kenaikan Suhu Permukaan & Presentase (\%) \\
\hline 1. & $0-2^{\circ} \mathrm{C}$ & 7.091 \\
2. & $2-4^{\circ} \mathrm{C}$ & 30.673 \\
3. & $4-6^{\circ} \mathrm{C}$ & 42.415 \\
4. & $6-8^{\circ} \mathrm{C}$ & 15.029 \\
5. & $>8^{\circ} \mathrm{C}$ & 4.790 \\
\hline \hline
\end{tabular}

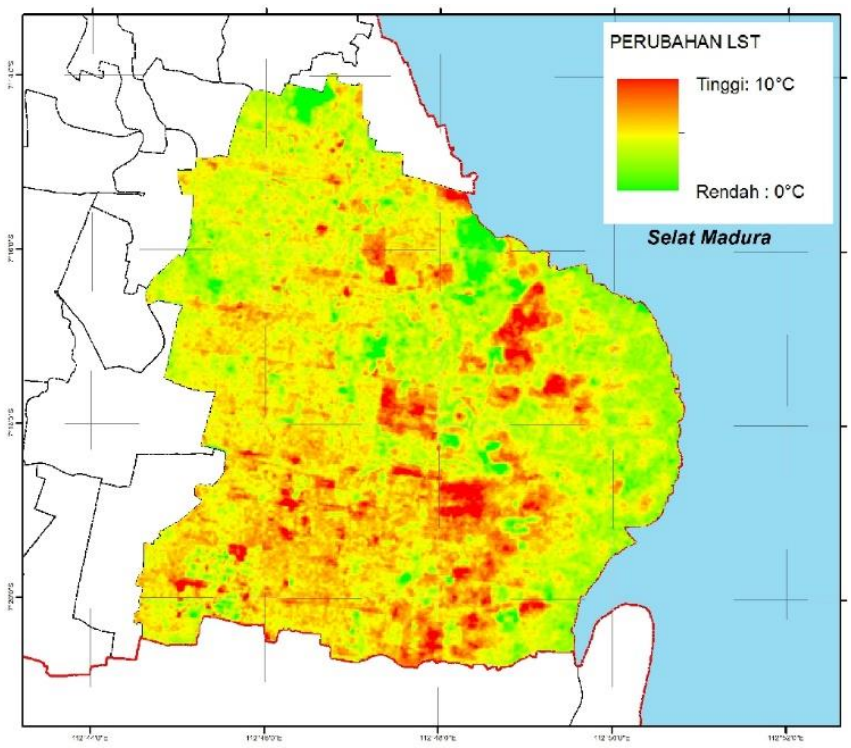

Gambar 8. Peta Perubahan Suhu Permukaan Wilayah Surabaya Timur Tahun 2001-2016.

\section{KESIMPULAN}

Berdasarkan hasil analisis yang telah dilakukan, maka dapat diperoleh kesimpulan bahwa terdapat kecenderungan peningkatan suhu permukaan pada periode tahun 2001-2016 dengan peningkatan pada periode $2001-2006$ sebesar $1,041^{\circ} \mathrm{C}$ atau sekitar 3,99\% dari suhu permukaan pada tahun 2001, pada periode tahun 2006 - 2011 terjadi peningkatan suhu permukaan sebesar $1,075^{\circ} \mathrm{C}$ atau sekitar $3,97 \%$ dari suhu permukaan pada tahun 2006, serta pada periode tahun 2011 - 
2016 terjadi peningkatan suhu permukaan yang paling signifikan yaitu sebesar $4,496^{\circ} \mathrm{C}$ atau sekitar $14,22 \%$ dari suhu permukaan pada tahun 2011. Peningkatan suhu permukaan ini memiliki suatu pola tersendiri yaitu peningkatan yang terjadi lebih besar dan lebih pesat cenderung terjadi pada bagian timur dan selatan Surabaya Timur. Bagian timur merupakan wilayah yang awalnya berupa pertambakan dan banyak berubah menjadi kawasan permukaan, sedangkan pada bagian selatan merupakan kawasan industri SIER.

\section{DAFTAR PUSTAKA}

“Overlay Analysis," 2016. [Online]. Available: http://resources.esri.com/help/9.3/arcgisdesktop/com/gp_toolref/geo processing/overlay_analysis.htm.

[2] S. M. E. S. Adiningsih, S. H. Soenarmo, Kajian Perubahan Distribusi Spasial Suhu Udara Akibat Perubahan Penutup Lahan.
LAPAN, 2000.

[3] B. S. A. H. Aditiyanti, L. M. Sabri, "Analisis Pengaruh Perubahan NDVI Dan Tutupan Lahan Terhadap Suhu Permukaan Di Kota Semarang," J. Geod. UNDIP, pp. 10-19, 2013.

[4] A. M. Bernales, "Modelling The Relationship Between Land Surface Temperature And Landscape Patterns of Land Use Land Cover Classification Using Multi Linear Regression Models," Int. Arch. Photogramm. Remote Sens. Spat. Inf. Sci., pp. 851-856, 2016.

[5] J. B. Campbell, Introduction to Remote Sensing. London, 1996.

[6] N. Debbage and M. Shepherd, The Urban Heat Island Effect And City Contiguity. 205AD.

[7] T. M. Lillesand and R. W. Kiefer, Penginderaan Jauh Dan Interpretasi Citra. Gajah Mada University Press, 1997.

[8] W. P. Lowry, "Empirical Estimation Of Urban Effects On Climate: A Problem Analysis," J. Appl. Meteorol., pp. 129-135, 1977.

[9] T. N. C. T. W. Owen and R. R. Gillies, "Assessment Of Satelite Remotely-Sensed Land Cover Parameters In Quantitively Describing The Climatic Effect Of Urbanization," Int. J. Remote Sens., pp. 1663-1681, 1975. 